\section{Sentinel Lymph Node Biopsy: Is It an Evolution of the Management of Cutaneous Melanoma?}

\section{TO THE EDITORS:}

We read with great interest the paper written by Leiter et al., but we think that significant issues in the sentinel node biopsy have not been addressed. ${ }^{1}$

Leiter stresses significant data concerning improvement in disease-free survival (DFS) for melanoma patients following sentinel node biopsy (SLNB) compared with patients without SLNB. However, these figures lose significance if correlated to the nonimprovement of survival data. $^{1,2}$

In our view this is the result of lead-time bias, the already known effect of cancer screening tests occurring when the asymptomatic period in the disease's natural history is disregarded.

SLNB does not improve survival. It merely shortens the detection time of eventual lymph node metastases, consequently prolonging DFS. There is no certainty concerning their progression. One potential bias in the SLN biopsy theory is that all positive SLNs inevitably progress to overt nodal disease if lymphadenectomy is not performed. However, strong evidence now indicates otherwise. Some micrometastases in the SLN, as in the case examined, are destined either for destruction by host-immune processes or for dormancy. ${ }^{3-5}$ The importance of micrometastases is well known in oncology because micrometastases are present in other form of tumors. In breast cancer, for example, nodes less than $0.2 \mathrm{~mm}$ in diameter are staged as node negative because these micrometastases do not impact survival. ${ }^{6}$

Therefore, we may not have the ability to predict which patient with microscopically node metastasis will develop clinical disease.

In the SLNB group, the "metastases diagnosis" is made when excising the melanoma in the asymptomatic period, clearly increasing DFS. The non-SLNB group has the same survival period, with shorter DFS because of certain clinical evidence of metastases.
SLNB patients are not actually living longer but only discovering their disease earlier. SLNB does not provide extra years "forward" but extra years "backward" of disease. Patients are exposed to possible iatrogenic risks and adjuvant therapies whose undemonstrated efficacy may worsen their quality of life. ${ }^{7}$

Vincenzo De Giorgi, MD, Marta Grazzini, MD, Federica Papi, MD, Alessia Gori, MD, Susanna Rossari, MD, and Torello Lotti, MD Department of Dermatology, University of Florence, Florence, Italy

e-mail: vincenzo.degiorgi@unifi.it

Published Online: 14 April 2010

(C) Society of Surgical Oncology 2010

\section{REFERENCES}

1. Leiter U, Buettner PG, Bohnenberger K, Eigentler T, Meier F, Moehrle M, et al. Sentinel lymph node dissection in primary melanoma reduces subsequent regional lymph node metastasis as well as distant metastasis after nodal involvement. Ann Surg Oncol. 2009;17:129-37.

2. Morton DL, Thompson JF, Cochran AJ, Mozzillo N, Elashoff R, Essner R, et al. Sentinel-node biopsy or nodal observation in melanoma. N Engl J Med. 2006;355:1307-17.

3. Gershenwald JE, Thomson W, Mansfield PF, Lee JE, Colome MI, Tseng $\mathrm{CH}$, et al: Multi-institutional melanoma lymphatic mapping experience: The prognostic value of sentinel lymph node status in 612 Stage I or II melanoma patients. J Clin Oncol. 1999;17:97683.

4. Carlson GW, Murray DR, Lyles RH, Staley CA, Hestley A, Cohen C. The amount of metastatic melanoma in a sentinel lymph node: Does it have prognostic significance? Ann Surg Oncol. 2003;10:575-81.

5. Spanknebel K, Coit DG, Bieligk SC, Gonen M, Rosai J, Klimstra DS. Characterization of micrometastastic disease in melanoma sentinel lymph nodes by enhanced pathology: Recommendations for standardizing pathologic analysis. Am J Surg Pathol. 2005;29: 305-17.

6. Chagpar A, Middleton LP, Sahin AA, Meric-Bernstam F, Kuerer HM, Feig BW, et al. Clinical outcome of patients with lymph node-negative breast carcinoma who have sentinel lymph node micrometastases detected by immunohistochemistry. Cancer. 2005;103:1581-6.

7. De Giorgi v, Leporatti G, Massi D, Lo Russo G, Sestini S, Papi F, et al. Sentinel lymph nodes in melanoma patients: evaluating the evidence. Oncology. 2006;71:460-2. 